\title{
ANALISIS SISTEM PENGENDALIAN KREDIT YANG EFEKTIF GUNA MENINGKATKAN PROFITABILITAS (Studi Pada PT. BPR. Bina Nusa Cabang Gresik)
}

\author{
Ana Fitriyatul Bilgies \\ Fakultas Ekonomi \\ Universitas Islam Darul 'ulum Lamongan \\ anafitriyatulbilgies@unisda.ac.id
}

\begin{abstract}
This study aims to determine the effectiveness of credit control to increase profitability at PT. BPR. Bina Nusa, Gresik Branch. The research method uses descriptive methods with a quantitative approach. The results showed that the credit policy adopted by PT. BPR. Bina Nusa Gresik Branch is said to be effective even though credit control is less than optimal because there is an increase in bad loans, but it does not affect the results of the calculation of profitability ratios namely Gross profit margin in 2015 amounted to 20.93\%, in 2016 amounted to 21.33\%, in 2017 amounted to $22.28 \%$, and 2018 amounted to 25.90\%. Net profit margin in 2015 was $15.70 \%$, in 2016 it was $17.73 \%$, in 2017 it was $20.07 \%$ and in 2018 it was $21.84 \%$. Return on assets in 2015 amounted to $5.41 \%$ in 2016 amounted to $6.33 \%$, in 2017 amounted to $6.85 \%$, in 2018 amounted to $6.67 \%$. The rate of return on loans in 2015 was $57.16 \%$, in 2016 it was $56.82 \%$, in 2017 it was $52.57 \%$, in 2018 it was $53.85 \%$. Return on equity in 2015 was $23.72 \%$. In 2016 it was $26.92 \%$. In 2017 it was $29.31 \%$ and in 2018 it was $30.73 \%$. as a whole can be said to be good because the achievement of the profitability ratio percentage of PT. BPR. Bina Nusa Gresik Branch is within the limits of Bank Indonesia regulations.
\end{abstract}

Keywords: Credit control, Profitability

\begin{abstract}
ABSTRAK
Penelitian ini bertujuan untuk mengetahui keefektifitasan dalam pengendalian kredit untuk meningkatkan profitabilitas pada PT. BPR. Bina Nusa Cabang Gresik. Metode penelitian menggunakan metode deskriptif dengan pendekatan kuantitatif. Hasil penelitian menunjukkan bahwa kebijakan kredit yang diterapkan oleh PT. BPR. Bina Nusa Cabang Gresik dikatakan efektif meskipun pada pengendalian kredit kurang optimal karena terdapat peningkatan kredit macet, namun hal itu tidak mempengaruhi hasil perhitungan rasio profitabilitas yaitu Gross profit margin pada tahun 2015 sebesar 20,93\%, tahun 2016 sebesar $21.33 \%$, tahun 2017 sebesar $22.28 \%$, dan tahun 2018 sebesar 25.90\%. Net profit margin pada tahun 2015 sebesar 15.70\%, tahun 2016 sebesar $17.73 \%$, tahun 2017 sebesar $20.07 \%$ dan pada tahun 2018 sebesar $21.84 \%$. Return on assets pada tahun 2015 sebesar 5.41\% tahun 2016 sebesar 6.33\%, tahun 2017 sebesar $6.85 \%$, tahun 2018 sebesar $6.67 \%$. Rate return on loans pada tahun 2015 sebesar $57.16 \%$, tahun 2016 sebesar $56.82 \%$, tahun 2017 sebesar $52.57 \%$, tahun 2018 sebesar $53.85 \%$. Return on equity pada tahun 2015 sebesar $23.72 \%$. Tahun 2016 sebesar 26.92\%. Tahun 2017 sebesar $29.31 \%$ dan tahun 2018 sebesar $30.73 \%$. secara keseluruhan dapat dikatakan baik karena pencapaian persentasi rasio profitabilitas PT. BPR. Bina Nusa Cabang Gresik berada pada batas ketentuan Bank Indonesia.
\end{abstract}

Kata kunci : Pengendalian kredit, Profitabilitas 


\section{PENDAHULUAN}

Kredit merupakan hal yang banyak dilakukan oleh setiap orang. Kredit merupakan salah satu bentuk fasilitas keuangan yang memungkinkan seseorang untuk meminjam dan membeli produk, kemudian membayarnya kembali dalam jangka waktu yang telah ditentukan oleh perusahaan. Perusahaan dalam memberikan kredit kepada nasabah, selalu dihadapkan dengan berbagai macam resiko, oleh karena itu perusahaan pemberi kredit harus selektif betul dalam memberikan kredit kepada nasabah.

Dalam rangka menghindari resiko yang cukup tinggi dalam pemberian kredit, maka perusahaan harus menerapkan manajemen resiko untuk meminimalisir resiko pembiayaan yang mungkin terjadi. Ada banyak cara yang bisa dilakukan untuk meminimalisir, salah upaya yang bisa dilakukan dengan menerapkan analisis yang akurat dan mendalam pada saat menilai kelayakan atas permohonan pembiayaan adalah dengan menerapkan analisis 5C yaitu character, capacity, capital, collateral, condition of economic.

PT. BPR. Bina Nusa Cabang Gresik merupakan perusahaan yang bergerak dalam bidang pemberian kredit, tentunya PT. BPR. Bina Nusa Cabang Gresik. Juga harus menerapkan berbagai macam strategi agar bisa meminimalisir kredit macet, supaya profitabilitas perusahaan terus meningkat, selain itu perusahaan juga harus mengkaji dan mencari solusi-solusi dari setiap permasalahan yang terjadi di perusahaan.

Penelitian yang hampir sama pernah dilakukan oleh (Prastiwi, 2017), mengambil judul Analisis pengendalian intern sistem pengendalian kredit berbasis Coso (Studi kasus di BPR Chandra Muktiartha). Hasil penelitian menunjukkan bahwa sistem pemberian kredit yang dilakukan oleh BPR. Chandra Muktiartha belum sepenuhnya dilakukan sesuai dengan kelima komponen pengendalian intern menurut COSO (Comitte of sponsoring organization).

Selain itu hasil penelitian yang dilkukan oleh (Tiyas, 2016), mengambil judul analisis sistem pengendalian intern pemberian kredit pada PT. Bank jatim Cabang Kediri, menunjukkan bahwa penerapan pengendalian internal dalam pemberian kredit pada PT, Bank Jatim Cabang Kota Kediri telah memadai.

Berdasarkan latar belakang tersebut, peneliti membuat penelitian dan mengambil Judul "Analisis Sistem Pengendalian Kredit Yang Efektif Guna Meningkatkan Profitabilitas" (Studi pada PT. BPR. Bina Nusa Cabang Gresik). 


\section{TINJAUAN PUSTAKA}

\section{Kredit}

Kata kredit bukan perkataan yang asing bagi kehidupan sehari-hari, tapi sudah menjadi kata-kata yang umum bagi masyarakat. Menurut Undang-Undang N0.10 Tahun1998 kredit adalah penyediaan uang atau tagihan yang dapat dipersamakan dengan itu, berdasarkan persetujuan atau kesepakatan antara bank dengan pihak lain yang mewajibkan pihak peminjam untuk melunasi utangnya setelah jangka waktu tertentu dengan pemebrian bunga. Sedangkan menurut (Rivai, 2007) Kredit adalah penyerahan barang atau jasa-jasa, uang dari suatu pihak (Kreditor) atas dasar kepercayaan kepada pihak lain (nasabah) dengan janji membayar dari penerima kredit pada tanggal yang telah disepakati kedua belah pihak.

\section{Tujuan Kredit}

Pemberian kredit memberikan tujuan tertentu. Tujuan pemberian kredit tidak terlepas dari misi bank. Menurut (Kasmir, 2004) tujuan pemberian kredit adalah sebagai berikut :

1. Mencari keuntungan

Tujuan utama pemberian kredit adalah untuk mencari keuntungan. Hasil keuntungan ini diperoleh dalam bentuk bunga yang diterima oleh bank sebagai balas jasa dan biaya administrasi kredit yang dibebankan pada nasabah.

2. Membantu usaha nasabah.

Tujuan selanjutnya adalah untuk membatu usaha nasabah yang membutuhkan dana, baik dana untuk investasi maupun dana untuk modal kerja. Dengan dan itu maka pihak debitur akan mengembangkan serta memperluas usahanya.

3. Membantu pemerintah.

Bagi pihak pemerintah semakin banyak kredit yang diberikan oleh pihak bank. Maka semakin meningkatkan jumlah kegiatan ekonomi yang terjadi. Mengingat semakin banyak kredit berarti adanya peningkatan pembangunan berbagai sector.

\section{Pengendalian Kredit}

Pengendalian merupakan salah satu fungsi manjemen. Dengan demikian, maka sudah menjadi kewajiban bagi manajemen untuk menciptakan suatu sistem pengawasan dari perusahaan dengan cara seefektif dan seefisien mungkin. Salah satu pengawasan tersebut adalah apa yang disebut dengan pengendalian. 
Pengendalian adalah proses, kebijakan, dan prosedur yang dirancang oleh manajemen untuk memastikan pelaporan keuangan yang handal dan pembuatan laporan keuangan sesuai dengan kerangka akuntansi yang berlaku. (Tuanakotta, 2015). Sedangkan menurut Hasibuan (2004:105) Pengendalian kredit adalah usaha-usaha untuk menjaga kredit yang diberikan agar tetap lancar, produktif dan tidak macet.

\section{Macam-macam Sistem Pengendalian Kredit}

Menurut (Sinungan, 2007) sistem pengendalian kredit terdiri dari beberapa macam, yaitu :

1. Internal control of credit adalah sistem pengendalian kredit yang dilakukan oleh karyawan bank bersangkutan. Cakupannya meliputi pencegahan dan penyelesaian kredit macet.

2. Audit control of credit adalah sistem pengendalian masalah yang berkaitan dengan pembukuan kredit. Jadi pengendalian atas masalah khusus, yaitu tentang kebenaran pembukuan kredit.

3. External control of credit adalah sistem pengendalian kredit yang dilakukan oleh pihak luar, baik oleh bank Indonesia atau akuntan public.

\section{Profitabilitas}

Profitabilitas adalah kemampuan suatu bank dalam menghasikan laba selama periode tertentu, juga bertujuan untuk mengukur efektivitas manajemen dalam menjalankan operasional perusahaannya.(Sawir, 2005). Menurut (Harahap, 2008) Profitabilitas adalah kemampuan perusahaan mendapat laba melalui semua kemampuan sumber daya yang ada seperti kegiatan penjualan, kas, modal, jumlah karyawan, jumlah cabang, dll.

Sedangkan menurut (Brigham, 2006) yang dimaksud profitabilitas adalah hasil bersih dari serangkaian kebijakan dan keputusan. Profitabilitas dapat ditetapkan dengan menghitung berbagai tolak ukur yang relevan. Salah satu tolak ukur tersebut adalah dengan rasio keuangan sebagai salah satu analisa dalam menganalisa kondisi keuangan, hasil operasi dan timgkat profitabilitas suatu perusahaan.

\section{Rasio Profitabilitas}

Menurut (Kasmir, 2005) Untuk melakukan pengukuran rasio ini memiliki beberapa jenis rasio yang masing-masing memiliki maksud dan tujuan yang tersendiri, yaitu : 


\section{Gross profit margin}

Rasio ini digunakan untuk mengetahui presentase laba dari kegiatan usaha murni dari bank yang bersangkutan setelah dikurangi biaya-biaya. Penghitungan gross profit margin bank secara sistematis menggunakan rumus :

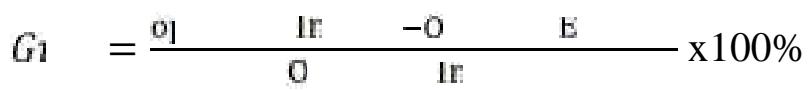

2. Net profit margin

Net profit margin merupakan rasio untuk mengukur kemampuan bank dalam menghasilkan net income dari kegiatan operasi pokoknya. Penghitungan net profit margin bank secara sistematis menggunakan rumus :

$$
N=\frac{\text { Net Income }}{\text { Operating Income }} X 100 \%
$$

3. Retrun on assets

Rasio ini digunakan untuk mengukur kemampuan manajemen dalam memperoleh profitabilitas dan manjeril efisien secara overall. Penghitungan ini menggunakan rumus :

$$
R=\frac{\mathrm{N} \text { in }}{\mathrm{T} \text { A }} \mathrm{X} 100 \%
$$

\section{Rate Retrun on Loans}

Analis ini digunakan untuk mengukur kemampuan manajemen dalam mengelola kegiatan pengkreditannya. Penghitungan Rate Retrun on Loans bank secara sistematis menggunakan rumus :

$$
R \quad R \quad 0 \quad L \quad=\frac{\mathrm{II}}{\mathrm{T}} \mathrm{In}-\mathrm{L} 100 \%
$$

\section{Retrun on Equity}

ROE merupakan rasio untuk mengukur kemampuan manajemen bankdalam mengelola capital yang ada untuk mendapatkan net income. Penghitungan ROE bank secara matematis menggunakan rumus :

$$
\mathrm{ROE}=\frac{n \quad \text { in }}{e} \mathrm{e} 100 \%
$$

\section{METODE PENELITIAN}

\section{Metode Penelitian}

Metode penelitian yang digunakan dalam penelitian ini adalah deskriptif dengan pendekatan kuantitatif. Tujuan dari penelitian deskriptif adalah untuk membuat deskripsi, gambaran atau lukisan secara sistematis, faktual dan akurat mengenai fakta-fakta, sifat- 
sifat serta hubungan antara fenomena yang diselidiki. (Nasir, 2005). Objek penelitian ini adalah PT. BPR. Bina Nusa Cabang Gresik. Dalam penelitian ini data yang digunakan adalah data sekunder dan data primer.

\section{Analisis Data}

Analisis data yang dilakukan dalam penelitian ini adalah analisis pengendalian kredit yang terdiri dari Internal Control of Credit, Audit Control of Credit, External Control of Credit. Dan Analisis rasio profitabilitas yang meliputi : Gross Profit Margin, Net Profit Margin, Retrun on Assets, Rate Retrun On Loans, Retrun on Equity

\section{HASIL DAN PEMBAHASAN}

\section{Sistem Pemberian Kredit}

Berdasarkan hasil analisis sistem pemberian kredit pada PT. BPR Bina Nusa Cabang Gresik secara keseluruhan sudah sesuai dengan sistem pemberian kredit yang baik, yaitu mulai dari prosedur pemberian kredit, prosedur penyelidikan dan analisis kredit, prosedur persetujuan permohonan kredit, prosedur pencairan fasilitas kredit, dan prosedur pelunasan fasilitas kredit. Organisasi pada manajemen kredit pun tidak adanya tanggungjawab ganda antar unit kerja yang ada pada PT. BPR Bina Nusa Cabang Gresik.

\section{Sistem Pengendalian Kredit}

Berdasarkan penelitian yang dilakukan, pengendalian kredit sangat perlu dilakukan untuk meminimaliskan kerugian yang diterima perusahaan pada saat peroses kredit berlangsung. Berikut data yang di peroleh dari PT. BPR. Bina Nusa Cabang Gresik :

\section{Data Overdue}

PT. BPR. Bina Nusa Cabang Gresik

\begin{tabular}{|c|c|c|c|}
\hline \multirow{2}{*}{ Periode } & Jumlah & \multicolumn{2}{|c|}{ Total Sisipiu Overdue } \\
\cline { 3 - 4 } & Nasabah & Nasabah & \% \\
\hline 2015 & 1.330 & 150 & 11.27 \\
\hline 2016 & 1.300 & 165 & 12.69 \\
\hline 2017 & 1.255 & 170 & 13.54 \\
\hline 2018 & 1.270 & 185 & 14.56 \\
\hline
\end{tabular}

Sumber : Data diolah Peneliti (2019)

Dari data diatas dapat diketahui bahwa PT. BPR. Bina Nusa Cabang Gresik dari peride 2015 sampai dengan 2018 Jumlah Nasabah yang mengalami kredit macet terdapat kenaikan. Hal tersebut akan mengakibatkan Profitabilitas PT. BPR. Bina Nusa mengalami penurunan, oleh karena itu diperlukan penagihan yang lebih efektif untuk 
mengatasi hal tersebut. Berikut ini sistem pengendalian kredit yang efektif yang telah dilakukan oleh PT. BPR. Bina Nusa Cabang Gresik, yaitu

1. Internal Control of Credit adalah dalam sistem pengendalian ini PT. BPR. Bina Nusa Cabang Gresik, memproses pengajuan yang persyaratannya lengkap sesuai dengan ketentuan yang telah ditetapkan perusahaan, melakukan survey, hingga melakukan kredit checking sebelum melakukan pencairan uang. Kemudian PT. BPR. Bina Nusa Cabang Gresik juga membentuk admin finance dan admin kolektor serta melakukan penagihan bagi nasabah telat dalam melakukan pembayaran.

2. Audit Control of Credit dalam sistem pengendalian ini PT. BPR. Bina Nusa Cabang Gresik selalu melakukan pengecekan tentang kebenaran pembukuan kredit.

3. External Control of Credit dalam sistem pengendalian ini PT. BPR. Bina Nusa Cabang Gresik juga bekerja sama dengan akuntan publik untuk menata sistem keuagannya.

\section{Profitabilitas}

Hasil analisis profitabilitas perusahaan PT. BPR. Bina Nusa Cabang Gresik, dapat dilihat sebagai berikut :

1. Gross Profit Margin PT. BPR. Bina Nusa Cabang Gresik.

\begin{tabular}{|c|c|c|c|}
\hline Tahun & $\begin{array}{c}\text { Operating Income- } \\
\text { Operating Expenses }\end{array}$ & $\begin{array}{c}\text { Operating } \\
\text { Income }\end{array}$ & GPM \\
\hline 2015 & 1.542 .112 .657 & 7.367 .785 .466 & $20,93 \%$ \\
\hline 2016 & 1.642 .563 .268 & 7.700 .464 .776 & $21.33 \%$ \\
\hline 2017 & 1.723 .547 .969 & 7.735 .654 .876 & $22.28 \%$ \\
\hline 2018 & 2.110 .061 .465 & 8.145 .785 .466 & $25.90 \%$ \\
\hline
\end{tabular}

Berdasarkan perhitungan GPM pada tabel, presentase GPM dari tahun 2015-2016 mengalami peningkatan $0,4 \%$, tahun $2016-2017$ meningkat $0,95 \%$ dan pada tahun 2017-2018 meningkat sebesar 3,62\%, artinya bahwa kemampuan PT. BPR. Bina Nusa Cabang Gresik. dalam menghasilkan laba dari oprasional usahanya dikatakan baik.

2. Net Profit Margin PT. BPR. Bina Nusa Cabang Gresik.

\begin{tabular}{|c|c|c|c|}
\hline Tahun & Net Income & Operating Income & NPM \\
\hline 2015 & 1.156 .765 .079 & 7.367 .785 .466 & $15.70 \%$ \\
\hline 2016 & 1.365 .675 .900 & 7.700 .464 .776 & $17.73 \%$ \\
\hline 2017 & 1.552 .645 .765 & 7.735 .654 .876 & $20.07 \%$ \\
\hline 2018 & 1.779 .675 .400 & 8.145 .785 .466 & $21.84 \%$ \\
\hline \multicolumn{2}{|l}{ Sumber : Data diolah Peneliti (2019) }
\end{tabular}


Berdasarkan perhitungan NPM pada tabel, presentase NPM mengalami peningkatan yaitu pada tahun 2015-2016 meningkat 2,03\% pada tahun 2016-2017 meningkat 2,34\% dan tahun 2017-2018 menigkat 1,77\%. Dalam hal ini NPM untuk mengukur kontribusi pendapatan operasional dalam memperoleh laba bersih pada PT. BPR. Bina Nusa Cabang Gresik dikatakan baik.

3. Retrun on Assets PT. BPR. Bina Nusa Cabang Gresik.

\begin{tabular}{|c|c|c|c|}
\hline Tahun & Net income & Total assets & ROA \\
\hline 2015 & 1.156 .765 .079 & 21.356 .765 .654 & $5,41 \%$ \\
\hline 2016 & 1.365 .675 .900 & 21.559 .423 .499 & $6,33 \%$ \\
\hline 2017 & 1.552 .645 .765 & 22.664 .886 .742 & $6,85 \%$ \\
\hline 2018 & 1.779 .675 .400 & 26.656 .329 .657 & $6,67 \%$ \\
\hline \multicolumn{2}{|l}{ Sumber : Data diolah Peneliti (2019) }
\end{tabular}

Pada perhitungan $R O A$ mengalami fluktuasi atau tidak stabilnya PT. BPR. Bina Nusa Cabang Gresik. dalam mengoptimalkan kemampuan manajemen dalam memperoleh profitabilitas yaitu pada tahun 2017-2018 yang mengalami penurunan presentase 0,18\%. Meskipun begitu Bank masih diatas standar BI (0,5\%-1,25\%) pada perhitungan ROA.

4. Rate Retrun On Loans PT. BPR. Bina Nusa Cabang Gresik.

\begin{tabular}{|c|c|c|c|}
\hline Tahun & Interest income & Total loans & Rate return on loans \\
\hline 2015 & 16.678 .444 .899 & 29.176 .687 .800 & $57,16 \%$ \\
\hline 2016 & 16.876 .465 .666 & 29.698 .069 .400 & $56,82 \%$ \\
\hline 2017 & 15.076 .645 .444 & 28.674 .718 .799 & $52,57 \%$ \\
\hline 2018 & 15.165 .749 .699 & 28.162 .076 .799 & $53,85 \%$ \\
\hline
\end{tabular}

Berdasarkan perhitungan diatas Rate Retrun On Loans PT. BPR. Bina Nusa Cabang Gresik. mengalami fluktuasi yaitu tidak stabilnya perusahaan dalam mengelola kreditnya sehingga PT. BPR. Bina Nusa Cabang Gresik memiliki masalah dalam tingkat profitabilitasnya. Pada tahun 2015-2016 mengalami penurunan 0,34\%. Pada tahun 2016-2017 mengalami penurunan 4,25\% dan pada tahun 2017-2018 mengalami peningkatan $1,28 \%$.

5. Retrun on Equity PT. BPR. Bina Nusa Cabang Gresik.

\begin{tabular}{|c|c|c|c|}
\hline Tahun & Net income & Equity & ROE \\
\hline 2015 & 1.156 .765 .079 & 4.875 .448 .387 & $23,72 \%$ \\
\hline 2016 & 1.365 .675 .900 & 5.072 .387 .055 & $26,92 \%$ \\
\hline 2017 & 1.552 .645 .765 & 5.297 .079 .470 & $29,31 \%$ \\
\hline 2018 & 1.779 .675 .400 & 5.790 .671 .448 & $30,73 \%$ \\
\hline
\end{tabular}


Persentase REO perusahaan selama 4 tahun berturut-turut mengalami peningkatan yaitu pada 2015-2016 meningkat sebesar 3,2\%, pada tahun 2016-2017 meningkat sebesar 2.39\%, dan tahun 2017-2018 meningkat sebesar 1,42\%. Rata-rata Retrun on Equity PT. BPR. Bina Nusa Cabang Gresik. masih diatas standar Bank Indonesia (5\%$12,5 \%)$ yaitu $24,56 \%$.

\section{SIMPULAN DAN SARAN}

\section{Simpulan}

Berdasarkan hasil penelitian tentang Analisis Sistem Pengendalian Kredit Yang Efektif Guna Meningkatkan Profitabilitas" (Studi pada PT. BPR. Bina Nusa Cabang Gresik). Dapat disimpulkan bahwa :

1. Dalam sistem pengendalian kredit ada dua faktor yaitu pemberian kredit dan penagihan kredit. Adapun dalam pemberian kredit pada PT. BPR. Bina Nusa Cabang Gresik. Sudah sesuai dengan Standart Operasional Prosedur (SOP) dan sudah sesuai dengan peraturan-peraturan perusahaan. Sedangkan dalam penanganan kredit atau kolektor OD (Over Due) kurang optimal. Tugas dan tanggung jawab staf perusahaan yang sudah sesuai dengan jobdish nya.

2. Keefektivitasan dalam upaya penyelamatan kredit macet yang dilakukan oleh pihak PT. BPR. Bina Nusa Cabang Gresik meliputi penagihan langsung, penarikan jaminan dan melakukan negoisasi terhadap nasabah. Meskipun memiliki kredit bermasalah pada tahun terakhir perhitungan rasio profitabilitas secara keseluruhan dikatakan baik meskipun pada net income total assets dan Rate retrun on loans mengalami fluktuasi.

\section{Saran}

1. Penulisa menyarankan agar lebih berhati-hati dalam menangani calon nasabah baru sehingga dapat meminimaliskan terjadinya kredit macet. Perlu peningkatan mengenai teori analisa pada saat pemberian kredit yang dilakukan.

2. Lebih mengoptimalkan kinerja kolektor untuk menangani konsumen yang sudah mengalami kredit macet sehingga dapat meminimaliskan kerugian perusahaan, serta mengadakan pengawasan kredit lebih ketat lagi dan efektif dalam menurunkan jumlah kredit macet yang terjadi. Melakukan pengrekrutan tenaga baru dibidang marketing atau AO sehingga dapat menambah pemasukan atau profitabilitas perusahaan 
EkoNiKa |Vol. 4, No. 2, September 2019 : 157-166

Doi : http://dx.doi.org/10.30737/ekonika.v4i2.437
Analisis Sistem Pengendalian .. (Bilgies)

$P-I S S N: \underline{2502-9304}$

E-ISSN : 2581-2157

\section{DAFTAR PUSTAKA}

Brigham, E. F. dan H. (2006). Fundamental Of Financial Management : Dasar-Dasar Manajemen Keuangan. Edisi 10. Jakarta: Salemba Empat.

Harahap, S. S. (2008). Analisis Kritis Atas Laporan Keuangan. Jakarta: Raja Grafindo Persada.

Kasmir. (2004). Bank dan Lembaga Keuangan Lainnya. Jakarta: PT. Raja Grafindo Persada.

Kasmir. (2005). Manajemen Perbankan, Cetakan Ke-13. Edisi Revisi. Jakarta: PT. Raja Grafindo Persada.

Nasir, M. (2005). Metode Penelitian. Jakarta: Ghalia Indonesia.

Prastiwi, D. R. (2017). No TitleAnalisis pengendalian intern sistem pengendalian kredit berbasis Coso (Studi kasus di BPR Chandra Muktiartha).

Rivai, V. dan A. P. V. (2007). Credit Management Handook. Jakarta: PT. Raja Grafindo Persada.

Sawir, A. (2005). Analisa Kinerja Keuangan dan Perencanaan Keuangan Perusahaan. Jakarta: PT.Sun.

Sinungan, M. (2007). Apa dan Bagaimana. Edisi Kedua. Jakarta: Bumi Aksara.

Tiyas, N. C. (2016). Analisis Sistem Pengendalian Intern Pemberian Kredit Pada PT. Bank Jatim Cabang Kediri. Universitas Nusantara.

Tuanakotta, T. M. (2015). Audit Kontemporer. Jakarta: Salemba Empat. 